\title{
Assessment of Public Health Risks Associated with Naphthalene Entering Residences and Commercial Space from Vapor Intrusion at MGP Sites*
}

\author{
Robin DeHate $^{1,2 \#}$, Brian Skelly ${ }^{2}$, Marie Bourgeois ${ }^{1}$, Giffe Johnson ${ }^{1}$, Raymond Harbison ${ }^{1}$ \\ ${ }^{1}$ Center for Environmental/Occupational Risk Analysis and Management, College of Public Health, University of South Florida, \\ Tampa, USA; ${ }^{2}$ GEI Consultants Inc., Valrico, USA. \\ Email: ${ }^{*}$ rdehate@geiconsultants.com
}

Received September $5^{\text {th }}, 2013$; revised October $7^{\text {th }}, 2013$; accepted November $9^{\text {th }}, 2013$

Copyright (C) 2013 Robin DeHate et al. This is an open access article distributed under the Creative Commons Attribution License, which permits unrestricted use, distribution, and reproduction in any medium, provided the original work is properly cited. In accordance of the Creative Commons Attribution License all Copyrights (C) 2013 are reserved for SCIRP and the owner of the intellectual property Robin DeHate et al. All Copyright (C) 2013 are guarded by law and by SCIRP as a guardian.

\begin{abstract}
Naphthalene, a constituent of coal tar, is a contaminant frequently found at former manufactured gas plants (MGP). Development at these sites has resulted in residential and commercial areas with potential exposures from vapor intrusion adversely affecting indoor air of residences and buildings. Naphthalene is routinely analyzed in soil vapor intrusion assessments for properties overlying and surrounding former MGP sites. The United States Environmental Protection Agency (EPA) has a proposed unit risk factor and the State of California has promulgated a unit risk factor for naphthalene. Naphthalene exposure from vapor intrusion is potentially a public health risk. The purpose of this study was to evaluate three sites located in the northeast United States to determine the frequency of naphthalene detection in indoor air. A total of 79 properties were included in the study. A total of 546 indoor air samples were analyzed for naphthalene on 161 occasions. Naphthalene concentrations ranged from 0.26 to $51 \mu \mathrm{g} / \mathrm{m}^{3}$ of air. Only 3 of the 546 indoor air samples detected naphthalene above the ninety-fifth percentile background value of $12 \mu \mathrm{g} / \mathrm{m}^{3}$ of air. Risk analysis indicated naphthalene vapor intrusion was not a public health risk among the 79 properties built on or near the former MGP sites.
\end{abstract}

Keywords: Soil Vapor Intrusion; Naphthalene; Volatile Organic Compounds; Risk Assessment; Manufactured Gas Plant

\section{Introduction}

Naphthalene is a polycyclic aromatic hydrocarbon (PAH) that is found in coal and oil-derived materials and is often present in soil, water, and air at and around industrial and manufactured gas plant (MGP) sites. Naphthalene is a volatile organic compound frequently used as an indicator chemical of potential manufactured gas plant (MGP) contamination [1]. During the early $20^{\text {th }}$ century, manufactured gas plants (MGP) were widely used for the purpose of generating a local gas supply through the conversion of coal into natural gas. The gasification of coal generates coal tar, an oily compound containing multiple volatile organic chemicals (VOCs) including benzene,

*Conflict of Interest: No authors have any competing interest related to this research.

${ }^{\#}$ Corresponding author. toluene, methylbenzenes, xylene isomers (BTEX) and semi-volatile organic compounds (SVOCs) such as acenaphthene, acenaphthylene, naphthalene, phenanthrene, phenols, and pyrene.

An estimated 1500 abandoned MGP sites in the US are thought to present a potential public health hazard to the surrounding properties redeveloped for commercial and residential use. The United States Environmental Protection Agency is just one of many state and federal environmental agencies that have recommended assessment and remediation for the MGP sites [2]. The cost of remediating these MGP sites may reach millions of dollars [3]. Since compounds like naphthalene may be present in non-aqueous phase liquids (NAPL), the concern has expanded from possible soil and groundwater contamination to the potential for soil vapor intrusion [4]. Inhalation exposure via soil vapor intrusion to the chemicals 
commonly found at MGP sites is a concern because of the potential for adverse effects on human health [5-9].

A major concern regarding the regulation of low level naphthalene exposure is the issue of naphthalene's poorly characterized potential for carcinogenicity. The Naphthalene State-of-the-Science Symposium (NS3) in 2006 cites numerous issues in the regulation of naphthalene as a carcinogen, including the lack high quality epidemiological studies that support general causation between low level naphthalene exposures and cancer in humans. This, combined with the ubiquitous nature of naphthalene exposure in outdoor air and common household products, makes the regulation of low level naphthalene from potential industrial contamination challenging [10].

The purpose of this study was to assess three abandoned MGP sites across the US Northeast for the potential of harmful soil vapor intrusion (SVI) of naphthalene and to quantify the concentration of naphthalene if detected. The results were analyzed to determine whether naphthalene presented an appreciable human health risk via soil vapor intrusion at the selected MGP sites. Regulatory guidance for the evaluation of low level naphthalene exposures is also explored.

\section{Methods}

\subsection{Site Evaluation}

This study evaluated 79 properties, including commercial and single family/multi-family residential properties with potential naphthalene SVI from three former MGPs located in the northeastern United States. These properties were between $0-2500$ feet of the plume or source material at each site. The former MGP sites all overlaid permeable glacial outwash sands. The properties adjacent to or overlying MGP tar source material and/or naphthalene plumes were assessed for naphthalene SVI. Each of the evaluated properties received potable water from municipal sources. In order to assess the effect of depth to groundwater on the SVI potential, each site was categorized by vadose zone (region of aeration above the water table): no vadose zone; water table within 6 feet of the building slab (0 - 6 feet vadose zone); and water table between 6 and 25 feet of the building slab ( $6-25$ feet vadose zone). The distance to the dissolved phase groundwater plumes ranged from 2 to 35 feet below ground surface (BGS).

Prior to assessing any possible vapor intrusion, a formal analysis of structural factors (basement, crawl spaces, etc.) that would contribute to the migration of soil vapor was performed. A building survey and chemical inventory was conducted to identify the presence or absence of such factors. Naphthalene is present in multiple comer- cial and consumer products (cigarettes, mothballs, insecticides, etc.) so its presence is not indicative of SVI [11]. The existence of HVAC systems, fireplaces and clothes dryers were included in the analysis as these can create a pressure differential which may provide a pathway for vapor intrusion.

\subsection{Sample Collection and Analysis}

Samples of indoor and ambient air were collected, in addition to sub slab, proxy sub slab or soil vapor samples. If they were present, groundwater samples were also collected. Both indoor and soil vapor samples were gathered using Summa ${ }^{\circledR}$ or equivalent canisters. Each soil vapor sample point was sampled beneath an enclosure enriched with helium gas to evaluate potential infiltration of ambient air during the collection of the soil vapor sample. Helium was not detected within soil vapor samples verifying the integrity of the soil vapor probe seal at the time of sampling and that the soil vapor samples were representative of subsurface conditions [1].

Sub-slab soil vapor samples were collected in those properties with a vadose zone detected beneath the building slab. Soil vapor samples were collected beneath surrogate caps such as a driveway or patio when the water table was present above the basement slab. Indoor air samples were collected in those properties without a vadose zone. The majority of the samples were collected from November 15 to March 31 to coincide with heating season in the northeastern United States.

\subsection{Risk Assessment}

Data from 546 indoor air samples were analyzed for naphthalene in accordance with USEPA method TO-14A or TO-15. An independent reviewer validated all analytical laboratory results. As previously described in DeHate, et al. 2011, this method directs a known volume of sample through a multisorbent concentrator [1]. Water vapor from the sample breaks through the concentrator. The amount of vapor is dependent upon sampling duration and concentrator composition. After concentration and drying are complete, the naphthalene is desorbed, entrained and focused using a small volume multisorbent or reduced temperature trap.

The samples are thermally desorbed and separated via gas chromatography. Helium is used as a tracer gas to verify the integrity of the soil vapor probe seal and ensured the samples were representative of the subsurface conditions. Analysis was conducted by Alpha Woods Hole in Westborough, Massachusetts, a New York State Department of Health approved laboratory for identification and quantification of sample constituents using high resolution gas chromatography (GC) and mass spectros- 
copy. Helium analysis was conducted using the American Society for Testing and Materials (ASTM) Method 1946. This data was then compared to both regulatory and proposed guidance values for health risk to draw inferences as to the safety of the exposures observed.

\section{Results}

\subsection{Exposure Assessment}

The comparative data base used in this study as background values was the New York State Department of Health (NYSDOH) Guidance for Evaluating Soil Vapor Intrusion in the State of New York, 2006. Appendix C of this document contained the NYSDOH 1997: Control Home Database. From 1989-1996, the NYSDOH collected 228 indoor and outdoor air samples from 53 residences used as control homes in New York State investigations. In this study control homes were defined and selected to represent homes with neighborhood, construction, and occupancy similar to homes being investigated for VOC impacts on indoor air. Control homes also had no unusual source of VOCs, such as past oil spill, recent refinishing or painting activities, or proximity to the VOC source being investigated. This data set contains the comparative values for naphthalene used in our study.

Sites A, B and C properties are described in Table 1. Nearly all of the obtained naphthalene concentrations fell within the background concentration range. Detected naphthalene concentrations ranged from 0.26 to $51 \mu \mathrm{g} / \mathrm{m}^{3}$. Three of the 546 indoor air samples detected naphthalene above the $95^{\text {th }}$ percentile background value of $12 \mu \mathrm{g} / \mathrm{m}^{3}$. All three of these detections were associated with Site A. Overall, naphthalene was detected in less than $1 \%$ of the 546 indoor air samples.

A critical review was conducted of the three sites where naphthalene was detected above background levels. One of these detections was determined to be the result of a consumer product containing naphthalene (mothballs) that was present in the residence, rather than SVI. At a second property, naphthalene was detected in a sump room air sample where impacted sump water was present. Naphthalene was not detected in seventy-one other samples taken at the same location during six separate sessions. Naphthalene was also detected in a sample from the second floor of the building. Seven other samples collected at the same property failed to detect naphthalene in the soil vapor or in the indoor air on the first floor.

We were unable to obtain the actual data set from the NYSDOH, so we compared the concentrations from our sites to the percentile categories from the NYDOH summary tables. Figures 1-3 describe the percent of concen-
Table 1. Summary of data collected at evaluated sites.

\begin{tabular}{lcccc}
\hline & Site A & Site B & Site C & Total \\
\hline Number of properties & 66 & 6 & 7 & 79 \\
Number of events & 143 & 9 & 9 & 161 \\
Number of samples & 508 & 22 & 16 & 546 \\
Minimum detection $\left(\mu \mathrm{g} / \mathrm{m}^{3}\right)$ & 0.26 & 0.26 & 0.42 & \\
Maximum detection $\left(\mu \mathrm{g} / \mathrm{m}^{3}\right)$ & 51 & 7.8 & 2.1 & \\
Number exceeding $12\left(\mu \mathrm{g} / \mathrm{m}^{3}\right)$ & 3 & 0 & 0 & 3 \\
\hline
\end{tabular}

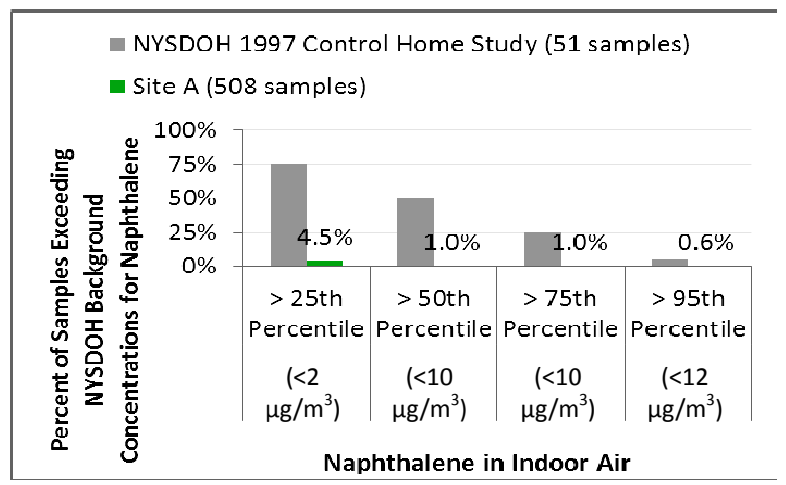

Figure 1. Results at Site A by quartile compared to NYSDOH indoor background level quartiles.

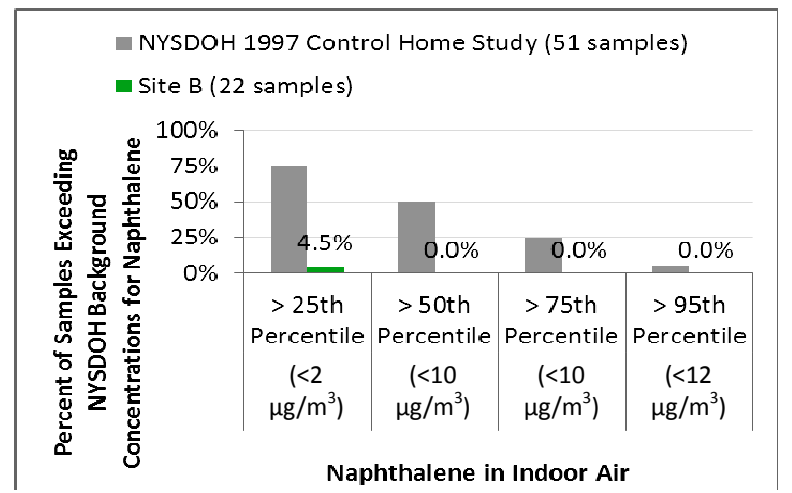

Figure 2. Results at Site B by quartile compared to NYSDOH indoor background level quartiles.

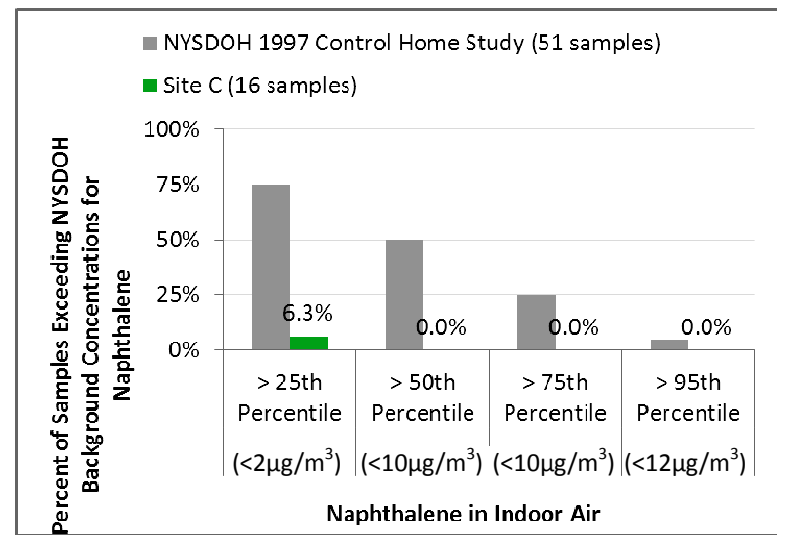

Figure 3. Results at Site C by quartile compared to NYSDOH indoor background level quartiles. 
trations at each site measured above the $25^{\text {th }}, 50^{\text {th }}, 75^{\text {th }}$, and $95^{\text {th }}$ percentile concentration in the NYSDOH summary tables. Figures 1-3 show that fewer samples in our data set exceed the NYSDOH percentile concentrations; meaning our site data was centered around lower concentrations of naphthalene than that of the NYSDOH data set.

\subsection{Risk Assessment}

Using the Unit Risk Factors of 1E-04 and 3.4E-05 (promulgated by the USEPA and the OEHHA of the State of California, respectively) in conjunction with the ambient naphthalene concentrations set forth by ATSDR, the risks are calculated and shown in Table 2. Most of these values exceed the USEPA acceptable risk range (1E-04 to 1E-06) and all exceed the acceptable risk set forth by states with more conservative values (1E-05; CA, MA). Similar results have previously been published for ambient air benzene levels; i.e. the generation of theoretical risk values in excess of regulatory limits for background exposures [12].

\section{Discussion}

This study assessed the potential public health risks posed by soil vapor intrusion from naphthalene contamination at residential and commercial properties abutting and overlying former MGP sites. Actually measuring indoor exposures provided valuable data as predictive models based on attenuation factors may be subject to large degrees of variability in their predictive value [13]. As previously stated, naphthalene was detected in less than $1 \%$ of the indoor samples, indicating negligible public health risk from naphthalene vapor intrusion impacting indoor air in the 76 properties built on or near the former MGP sites. Additionally, only 3 of the 546 indoor air samples registered naphthalene concentrations above the ninety-fifth percentile background value of $12 \mu \mathrm{g} / \mathrm{m}^{3}$ of air. These 3 detections could be explained by sources of naphthalene other than soil vapor intrusion from the former MGP sites. Overall, the measurements are consistent with other investigations of background levels of indoor naphthalene that typically range from $0.89 \mu \mathrm{g} / \mathrm{m}^{3}$ to $3 \mu \mathrm{g} / \mathrm{m}^{3}$, occasionally ranging as high as $200 \mu \mathrm{g} / \mathrm{m}^{3}$ [14].

The majority of the buildings and residences in this study were built in the late 1950 s to early 1960 s; however some of these buildings were over 100 years old. The residential buildings were primarily wood frame over a concrete foundation and a basement. Several of the structures included crawl spaces and basements with soil rather than concrete floors. The commercial buildings were generally concrete block with concrete foundations and basements. The majority of the structures assessed used sumps to capture groundwater under and around basements. Age and construction type of the buildings appeared to have limited impact on SVI. Factors such as natural attenuation and a protective layer of clean groundwater between the building and the naphthalene plume can act to mitigate SVI. Though internal building pressure is known to affect the potential for vapor intrusion, this did not appear to be a factor in this study [15]. Additionally, some bacteria use contaminants as a carbon source reducing or sometimes even eliminating the VOCs available for SVI [16]. It is likely that the substantive exposures measured in this study are a result of background exposure and consumer product use rather than contamination from former MGP activity.

According to the International Agency for Research on Cancer (IARC) and the National Toxicology Program (NTP), naphthalene is reasonably anticipated to be a human carcinogen $[17,18]$. This conclusion is currently being evaluated by the USEPA, ATSDR and other federal agencies. The USEPA has published a document entitled "External Review Draft Toxicological Review of Naphthalene-In Support of Summary Information on the Integrated Risk Information System (IRIS) ("Draft Review"). This document sets forth proposed information

Table 2. Carcinogen risks for various concentrations of naphthalene calculated with USEPA methodology.

\begin{tabular}{|c|c|c|c|c|}
\hline $\begin{array}{l}\text { Naphthalene concentration } \\
\text { range }\left(\mu \mathrm{g} / \mathrm{m}^{3}\right)\end{array}$ & Location & Outdoors/Indoors & $\begin{array}{c}\text { EPA Risk } \\
\text { Level/Range }\end{array}$ & $\begin{array}{l}\text { CAL EPA Risk } \\
\text { Level/ Range }\end{array}$ \\
\hline 1 & Urban Household & Indoors (Nonsmoking Household) & $1 \mathrm{E}-04$ & $3.4 \mathrm{E}-05$ \\
\hline 2.2 & Urban Household & Indoors (Smoking Household) & $2.2 \mathrm{E}-04$ & $7.5 \mathrm{E}-05$ \\
\hline $0.4-170$ & 11 US Urban Cities & Outdoors & $4 \mathrm{E}-05-1.7 \mathrm{E}-02$ & $1.4 \mathrm{E}-05-5.8 \mathrm{E}-03$ \\
\hline 0.94 & 11 US Urban Cities & Outdoors (median range) & $9.4 \mathrm{E}-05$ & $3.2 \mathrm{E}-05$ \\
\hline $0.33-9.7$ & North Carolina Low Income Homes & Indoors & $3.3 \mathrm{E}-05-9.7 \mathrm{E}-04$ & $1.2 \mathrm{E}-05-3.3 \mathrm{E}-04$ \\
\hline $0.57-1.82$ & North Carolina Low Income Homes & Outdoors & $5.7 \mathrm{E}-05-1.82 \mathrm{E}-05$ & $1.9 \mathrm{E}-05-6.2 \mathrm{E}-05$ \\
\hline $0.42-4.6$ & New Jersey & Outdoors & $4.2 \mathrm{E}-05-4.6 \mathrm{E}-04$ & $1.4 \mathrm{E}-05-1.6 \mathrm{E}-04$ \\
\hline
\end{tabular}


for updating IRIS' entry on naphthalene. Since USEPA's IRIS database is a primary tool used by federal and state regulators to establish site remediation requirements, the Agency's on-going review and proposed revisions to IRIS will likely influence how naphthalene is regulated, manufactured, and utilized in the future.

According to this document, naphthalene is carcinogenic, and the proposed toxicity values may decrease both residential and industrial soil screening concentrations (Regions III RBC and 9 PRG) by an order of magnitude or greater. Additionally, this document indicates that groundwater and SVI values would exceed those found in urban fills and natural soils. As a result, this publication carries serious implications for the investigation and cleanup requirements of MGP sites. Three regulations carry particular implications: 1) where site soil has already been remediated and the owner must evaluate the potential impacts of remaining concentrations and the prospect of future regulatory action; 2) where site soil is still in the assessment or remedial design phase; and 3) where groundwater concerns must be addressed [19].

The USEPA has promulgated a draft unit risk factor (URF) for naphthalene of 1E-04 per $\mu \mathrm{g} / \mathrm{m}^{3}$ of exposure. The Office of Environmental Health Hazard Assessment (OEHHA) of the State of California has set a unit risk factor of $3.4 \mathrm{E}-05$ per $\mu \mathrm{g} / \mathrm{m}^{3}$ for the evaluation of human health risks at contaminated sites. These risk levels are considered upper end, mostly due to the fact that: 1) current laboratory analyses for air samples rarely provide detection limits in the sub-ppb range; 2) estimations of risk from ambient exposures to naphthalene in both indoor and outdoor air result in risks to humans above regulatory guidelines; and 3) with the historic omnipresence of naphthalene use as both an industrial and domestic pesticide, a clear association between naphthalene exposures and human cancers should have been elucidated, however, evaluation by ATSDR (2005) has maintained that no cohort or morbidity studies have been identified to establish naphthalene as a human carcinogen [20].

These proposed changes to risk evaluation are based on NTP bioassay data relevant to exposures several orders of magnitude higher than environmental exposures and limited epidemiological data pertinent to assessing naphthalene carcinogenicity, which are generally viewed as inadequate for determining human carcinogenicity of naphthalene [17,18,21]. Price and Jayjock (2008) compared the exposures from the NTP bioassay results that induced cancer in animals to background exposures and found that the bioassay levels were 3000 - 10,000 times higher than the levels of exposure received from ambient air [22]. As well, levels of exposure for individuals in homes using mothballs are still 10- to 100-fold lower than the levels used in the bioassay. This is consistent with the results of the current study which found a maximal exposure of $51 \mu \mathrm{g} / \mathrm{m}^{3}$, and a total of 3 measurements of 546 greater than $12 \mu \mathrm{g} / \mathrm{m}^{3}$ which can be compared to the exposures of $52,400-314,400 \mu \mathrm{g} / \mathrm{m}^{3}$ for respiratory epithelial adenomas in male rats, olfactory epithelial neuroblastomas in female rats, and pulmonary bronchial adenomas in female mice $[23,24]$.

Not only do the exposures measured in this study fall substantially below exposures necessary to produce cancer in animals, the absence of reliable epidemiological data raises a fundamental question regarding the relevancy of the animal findings to carcinogenicity in humans. Some factors in question include increased lung metabolism in rodents in a study that was dependent on a saturated metabolic system, the potential for species specific metabolism in the rat nasal olfactory epithelium, differential nasal passage anatomy between rats and humans, and the use of a maximum tolerated dose approach, which may not adequately characterize lower dose mechanisms of carcinogenesis if they are present [25].

Additional researches to better compare the cross-species metabolic activities and to assess impacts at lower exposure levels to better define any dose-response relationship is ongoing among regulatory agencies. A reassessment of the toxicological potential of naphthalene may lead to significantly altered regulatory requirements applicable to the manufacture, use, management, and disposal of naphthalene. It will be important to rely on data that adequately characterizes risk from relevant environmental and occupational exposure levels to prevent the gross overestimation of risk of low level naphthalene exposure, putting background levels into the range of non-compliance. The results from this study indicate that naphthalene exposures from previous MGP sites are similar to background exposures and exposures from use of common household products. If naphthalene were to become the primary risk driver at previous MGP sites, it may produce the untoward effect of increasing cleanup costs without benefit to the public health.

\section{Conclusion}

Based on the results of this study, naphthalene did not present a health risk via soil vapor intrusion for the human population surrounding these former MGP sites. MGP associated vapors would need to permeate through several pathways into residential and commercial buildings in order to accumulate in sufficient concentrations to present an unacceptable risk to human health. If naphthalene was detected in buildings and residences, it was due to a combination of background naphthalene, vola- 
tilization from contaminated groundwater, and use of consumer products containing naphthalene.

\section{Acknowledgements}

This study was supported in part by GEI Consultants Inc. and the Center for Occupational/Environmental Risk Analysis and Management, College of Public Health, University of South Florida, Tampa, Florida.

\section{REFERENCES}

[1] R. B. DeHate, G. T. Johnson and R. D. Harbison, "Risk Characterization of Vapor Intrusion in Former Manufactured Gas Plant Sites," Regulatory Toxicology and Pharmacology, Vol. 59, No. 2, 2011, pp. 353-359. http://dx.doi.org/10.1016/j.yrtph.2010.12.001

[2] United States Environmental Protection Agency, "Compendium of Methods for the Determination of Toxic Organic Compounds in Ambient Air, 2nd Edition, Compendium Method TO-15 Determination of Volatile Organic Compounds (VOCs)," Air Collected in Specially-Prepared Canisters and Analyzed by Gas Chromatography/ Mass Spectrometry (GC/MS), Center for Environmental Research Information, Office of Research and Development, Cincinnati, 1999.

[3] Electric Power Research Institute, "50 MGP Site Management Portfolio," Federal Register, Vol. 77, No. 88, 2008, pp. 26751-26755.

[4] L. Turczynowicz and N. I. Robinson, "Exposure Assessment Modeling for Volatiles-Towards an Australian indoor vapor intrusion model," Journal of Toxicology and Environmental Health, Part A, Vol. 70, No. 19, 2007, pp. 1619-1634.

http://dx.doi.org/10.1080/15287390701434711

[5] D. J. Vorhees, W. H. Weisman and J. B. Gustafson, "Human Health-Risk Based Evaluation of Petroleum Release Sites: Implementing the Working Group Approach," Total Petroleum Hydrocarbon Criteria Working Group, Vol. 5, Amherst Scientific Publishers, Amherst, 1999.

[6] T. E. McHugh, L. Beckley, D. Bailey, K. Gorder, E. Dettenmaier, I. Rivera-Duarte, S. Brock and I. C. MacGregor, "Evaluation of Vapor Intrusion Using Controlled Building Pressure," Environmental Science \& Technology, Vol. 46, No. 9, 2012, pp. 4792-4799. http://dx.doi.org/10.1021/es204483g

[7] G. J. Kullman and R. A. Hill, "Indoor Air Quality Affected by Abandoned Gasoline Tanks," Applied Occupational and Environmental Hygiene, Vol. 5, No. 1, 1990, pp. 36-37.

http://dx.doi.org/10.1080/1047322X.1990.10389585

[8] M. L. Fischer, A. J. Bentley, K. A. Dunkin, A. T. Hodgson, W. W. Nazaroff, R. G. Sextro and J. M. Daisey, "Factors Affecting Indoor Air Concentrations of Volatile Organic Compounds at a Site of Subsurface Gasoline Contamination," Environmental Science \& Technology, Vol. 30, No. 10, 1996, pp. 2948-2957.

http://dx.doi.org/10.1021/es950912e
[9] C. L. Moseley and M. R. Meyer, "Petroleum Contamination of an Elementary School: A Case History Involving Air, Soil-Gas, and Groundwater Monitoring," Environmental Science \& Technology, Vol. 26, No. 1, 1992, pp. 185-192. http://dx.doi.org/10.1021/es00025a023

[10] F. Y. Griego, K. T. Bogen, P. S. Price and D. L. Weed, "Exposure, Epidemiology and Human Cancer Incidence of Naphthalene," Regulatory Toxicology and Pharmacology, Vol. 51, No. 2, 2008, pp. S22-S26. http://dx.doi.org/10.1016/j.yrtph.2008.02.003

[11] P. C. Johnson, R. A. Ettinger, J. Kurtz, R. Bryan and J. E. Kester, "Migration of Soil Gas Vapors to Indoor Air: Determining Vapor Attenuation Factors Using a ScreeningLevel Model and Field Data from the Cdot-Mtl Denver," Colorado Site, American Petroleum Institute, 2002.

[12] G. T. Johnson, S. C. Harbison, J. D. McCluskey and R. D. Harbison, "Characterization of Cancer Risk from Airborne Benzene Exposure," Regulatory Toxicology and Pharmacology, Vol. 55, No. 3, 2009, pp. 361-366. http://dx.doi.org/10.1016/j.yrtph.2009.08.008

[13] Y. Yao, R. Shen, K. G. Pennell and E. M. Suuberg, "Examination of the Influence of Environmental Factors on Contaminant Vapor Concentration Attenuation Factors Using the U.S. EPA's Vapor Intrusion Database," Environmental Science \& Technology, Vol. 47, No. 2, 2013, pp. 906-913.

[14] S. Batterman, J. Y. Chin, C. Jia, C. Godwin, E. Parker, T. Robins, P. Max and T. Lewis, "Sources, Concentrations, and Risks of Naphthalene in Indoor and Outdoor Air," Indoor Air, Vol. 22, No. 4, 2012, pp. 266-278.

[15] T. E. McHugh, J. A. Connor and F. Ahmad, "An Empirical Analysis of the Groundwater-to-Indoor-Air Exposure Pathway: The Role of Background Concentrations in Indoor Air," Environmental Forensics, Vol. 5, No. 1, 2004, pp. 33-44. http://dx.doi.org/10.1080/15275920490424024

[16] M. Vidali, "Bioremediation. An Overview," Pure and Applied Chemistry, Vol. 73, No. 7, 2001, pp. 1163-1172. http://dx.doi.org/10.1351/pac200173071163

[17] International Agency for Research on Cancer, "Traditional Herbal Medicines, Some Mycotoxins, Naphthalene, and Styrene," IARC Monographs on the Evaluation of Carcinogenic Risks to Humans, Vol. 82, IARC, Lyon, 2002.

[18] United States Environmental Protection Agency, "Integrated Risk Information System (IRIS) Toxicological Profile 0436," Naphthalene, 1998.

[19] G. Garvey, R. DeHate, E. A. Kazmarek and C. Geiger, "Implications of Naphthalene Carcinogenicity for MGP Investigation and Cleanup," Electric Power Research Institute, Atlanta, 2007.

[20] Agency for Toxic Substances and Disease Registry, "Toxicological Profile for Naphthalene 1-Methylnaphthalene, and 2-Methylnaphthalene," U.S. Department of Health and Human Services, Public Health Service, Atlanta, 2005.

[21] United States Environmental Protection Agency, "Building Assessment and Survey Evaluation (BASE 1994- 
1996)," 2001.

[22] P. S. Price and M. A. Jayjock, "Available Data on Naphthalene Exposures: Strengths and Limitations," Regulatory Toxicology and Pharmacology, Vol. 51, No. 2, 2008, pp. 15-21. http://dx.doi.org/10.1016/j.yrtph.2007.10.010

[23] National Toxicology Program, "Toxicology and Carcinogenesis Study of Naphthalene in B6C3F1 Mice (Inhalation Studies)," Technical Report Series No. 410, 1992.
[24] National Toxicology Program, "Toxicology and Carcinogenesis Study of Naphthalene in F344/N Rats (Inhalation Studies)," Technical Report Series No. 500, 2000.

[25] J. R. Lewis, "Naphthalene Animal Carcinogenicity and Human Relevancy: Overview of Industries with Naphthalene-Containing Streams," Regulatory Toxicology and Pharmacology, Vol. 62, No. 1, 2012, pp. 131-137. http://dx.doi.org/10.1016/j.yrtph.2011.12.004 